\title{
Integrating Intrusion Detection Model Using Ensemble of Classifiers and Extreme Learning Machine
}

\author{
Rayees Ahmad Sheikh ${ }^{1}$, Abid Ud Din Wani ${ }^{2}$, Abhishek Bhardwaj ${ }^{3}$ \\ ${ }^{1}$ Research Scholar, CT Institute of Engineering Management and Technology Jalandhar, Punjab, India \\ ${ }^{2}$ Research Scholar, CT Institute of Engineering Management and Technology, Jalandhar, Punjab, India \\ ${ }^{3}$ Assistant Professor Dept. Of CSE/IT, CT Institute of Engineering Management and Technology Jalandhar, \\ Punjab India \\ E-mail ID: sheikhrayees24@gmail.com, waniaabid369@gmail.com
}

The Intrusion detection from the last some decades are very important for current as well as for present networks. In the recent times many new methods have been used for IDS with machine learning technique and analysis for huge data is very much suitable. But the techniques like WMV (weighted majority voting) which have large dataset will take much more amount of time with this there is degradation of results whenever increasing the dataset. For this problem this paper focuses on the Extreme learning machine would be the best suitable for IDS with the analysis of big data and improving the accuracy. The proposed technique will integrate Mutual information ranking filter and attribute ranking feature selection with ELM technique. The Mutual information technique will implement attribute selection and will analyse proposed technique performance MI-ELM technique with algorithms like Modified Naïve Bayes, Support vector machine, LP Boosting and also hybrid of these three algorithms with respect to Precision, Recall. F-measure, accuracy, the (KS) Kappa statistic, Incorrectly and Correctly (CI) classified instances, RMSE (Root of Mean square erratum or error) and RRE (Root relative of error). There will be analysis of the dataset on according to basis of traffic is it normal or abnormal and the experimental results has shown that there will be increased accuracy in comparison with the classifiers.

Key words- Intrusion detection, Mutual information, Extreme Learning machine, Group of classifiers.

\section{INTRODUCTION}

\section{I} confidential information. Intrusions enter systems with the motives to copying files and running duplicate software and also defacement on the servers took place. There are two types Host IDs and NIDs. The Intrusion detection can glance the systems and if something suspicious happens the prompt will be given and very well monitored. Host-based is first type as well as first layer of IDS and each individual system had one IDS. The second layer is Network IDS and it very much easy to deploy and one IDS will be used at a time with many systems. Intrusion detection has been mainly classified into two optimal categories. Misuse/signature is technique in which specific rules have been defined and according to that rules suspicious activities have been detected very well but only those which are familiar. The Anamoly has capability with better rules it can detect both known and unfamiliar. The Mutual information is actually amount of the information sending and received. It contained the conditional probability with symmetric properties and the positive values means nonnegative. They are expressed to entropies and joint entropies. It is actually the proposed technique combining with the extreme learning machine and which is a new data driven tool also, an innovative idea of neural network uses a state of feed forward single/multiple network algorithm to provide very near solution. Some particular type of problems has been solving and it is machine learning setup and had multiple and single layers.

\section{Background Details:}

Thaseen et al. [1] have proposed Chi- Square feature selection which reduces the dimensionality of the specific attributes. Their aim was to find the main critical features as well as better accuracy for the Intrusion detection model. In this they have used Majority voting technique in which it notices the votes of each and every classifier like election protocol. The classifier which gives more votes in comparison with the other classifiers has been selected. The classifier (MNB), (SVM) and LP Boosting used for building the optimal Intrusion detection. The dataset performance well analysed and new description of benchmark DARPA Intrusion detection. It shows good generalisation and improved accuracy i.e.,

their suggested model when combining with classifiers. The majority voting of final classifier has been predicted and the experimental results have shown Distibuted denial of service, R2L and normal have been detected. 
Kausar et al. [2] have suggested principal component analysis- based mechanism (PCA) for the SVM intrusion detection system. In present performance factor and training overhead are the drawbacks of several Intrusion detection. The very much increased efficiency and the reduce very less false prompts with the maximising diagnosis rate. Main limitation in processing of the raw features of classifiers is much increasing complexity aritecture with accuracy reduce when detection increase. The processing of classifier overhead is a problem and for this motive have been use PCA. It can transform attributes into big dimension space and old minimising method by abstract several groups from attribute vector computing by the PCA. Now, these subsets separately train as well as test system through related resources and manipulate sensitivity. There is a lot of work shows maximising accuracy. Dhanabal et al. [3] have proposed the special Classification algorithm with the better evaluation of the data set. Basically, it is refined version of data set is KDD'99 (NSL-KDD) its predecessor dataset. The analysis of NSL-KDD dataset classification algorithms has the plenty of effectiveness and the study in network diagnosis anomalies. Therefore, the analysed relationship of protocols in network traffic are available patterned. Data mining classification algorithm are through the WEKA tool. The data set NSL-KDD of the analysis result best applicant data set to test feature IDS performance. Furthermore, CFS increases accuracy and the dimensionality minimizes as well as reduce the detection. Akashdeep et al. [4] have suggested intelligent system intrusion detection system which have potential to perform correlation and the information gain to perform well feature ranking firstly. So, to recognise the useless and useful attributes by using the Novel approach. The feedforward networks reduced the attributes of the networks for the testing on the KDD 99 dataset. Several instances of training before the preprocessing and then normalise the data. And the intelligently system behaves the categories into normal and attack classes. Their aim was that the attributes reduction system like in normal system to perform in same degree. They have tested five types of dataset so all average and unique results of data sates are reported. Zainal et al. [5] have proposed the ensemble in which sorting of the unique classes in which everyone have a learning model. The methods in this structure are LGP, Adaptive neural, ANFI and Random forest, integrating of many learning models shows increasing in diagnosis on the network traffic for accuracy. The limitation of this paper was many classification trees gather and results on unique address was capable to variance dataset with which machine knowledge method will unsuccessful to address it. Zhang et al. [6] have proposed that the wellstructured of the Hybrid system which actually overcomes the drawbacks of more wrong positive rate in anomaly detection and cannot detect the unknown intrusions by misuse. The Random forest algorithm in both cases misuse and anomaly where been integrated. Their proposed result showed increased detection on NIDS with great performance on misuse and anomaly detection usage. Pietraszek et al. [7] have suggested two best optimal approaches of complementary and the orthogonal to minimize several wrong positives by with alert process Intrusion detection in machine learning and also in the data mining. The alert system and these both methods work together. In real and the simulated environment wrong positive have been very minimized. Mukherjee et al. [8] have suggested that the method for attribute reduction vitality based to recognise the essential input reduction attributes. In their work, they have used Naïve Bayes classifier and it is efficient dataset minimization for Intrusion detection. The minimized features of empirical results give performance to IDS as well as effective for network IDS. Panda et al. [9] have proposed that the Intrusion detection in anomaly based was given naïve Bayes for data mining algorithm is very much efficient. The experimental results show detection increases on network. They have shown wrong positives, computation time and cost better performances when compared with the neural network back propagation. Daejoon et al [10] have proposed that the neural network with cost ratio of wrong positive as well as wrong false errors. The neural network in first step develops and in second phase performance will be analysed, errors of asymmetric costs. In the experimental result of IDS network shows performance by higher accuracy.

This paper organises as follow: section II discusses various intrusion models. Section III describes comparative analysis IV Research methodology. Section $\mathrm{V}$ describes proposed method with experimental results and the last section VI concludes paper 
3. COMPARATIVE ANALYSIS: Research scholars and professionals have used many techniques and methods In the Intrusion detection models

Table I Comparative analysis

\begin{tabular}{|c|c|c|c|c|c|}
\hline $\begin{array}{l}\text { S. } \\
\text { No }\end{array}$ & $\begin{array}{c}\text { Context of } \\
\text { research }\end{array}$ & $\begin{array}{c}\text { Techniques } \\
\text { used }\end{array}$ & $\begin{array}{c}\text { Problem } \\
\text { Discussed }\end{array}$ & Advantages & Authors \\
\hline 1 & $\begin{array}{c}\text { Characteristics } \\
\text { attributes for attack } \\
\text { and normal traffic }\end{array}$ & $\begin{array}{l}\text { Weighted } \\
\text { majority } \\
\text { voting } \\
\text { technique }\end{array}$ & $\begin{array}{c}\text { Combining } \\
\text { several } \\
\text { techniques with } \\
\text { this detection } \\
\text { reduces }\end{array}$ & $\begin{array}{l}\text { Maximising accuracy } \\
\text { when integrate with } \\
\text { several classifiers. }\end{array}$ & $\begin{array}{c}\text { Thaseen } e t \\
\text { al. }\end{array}$ \\
\hline 2 & $\begin{array}{l}\text { Having possible } \\
\text { feature reduction } \\
\text { with maximum } \\
\text { accuracy }\end{array}$ & $\begin{array}{c}\text { (PCA) } \\
\text { Principal } \\
\text { Component } \\
\text { Analysis }\end{array}$ & $\begin{array}{l}\text { Accurateness of } \\
\text { attack detection }\end{array}$ & $\begin{array}{c}\text { performance increase } \\
\text { when the attributes } \\
\text { decrease }\end{array}$ & $\begin{array}{c}\text { Kausar et } \\
\text { al. }\end{array}$ \\
\hline 3 & $\begin{array}{l}\text { Integrity of } \\
\text { algorithms }\end{array}$ & $\begin{array}{c}\text { Classification } \\
\text { Specific } \\
\text { algorithm }\end{array}$ & $\begin{array}{c}\text { Network } \\
\text { traffic } \\
\text { generate by } \\
\text { attacks }\end{array}$ & $\begin{array}{l}\text { Refining } \\
\text { strengthen }\end{array}$ & $\begin{array}{c}\text { Dhanabal } \\
\text { et al. }\end{array}$ \\
\hline 4 & $\begin{array}{l}\text { Characteristics } \\
\text { identified worthy } \\
\text { and motive less }\end{array}$ & $\begin{array}{l}\text { Intrusion } \\
\text { detection } \\
\text { system New } \\
\text { intelligent }\end{array}$ & $\begin{array}{l}\text { Complication } \\
\text { and } \\
\text { accumulation } \\
\text { intensity }\end{array}$ & $\begin{array}{c}\text { Efficiently } \\
\text { System operates }\end{array}$ & $\begin{array}{c}\text { Akashdeep } \\
\text { et al. }\end{array}$ \\
\hline 5 & $\begin{array}{l}\text { Sorting and } \\
\text { grouping in } \\
\text { learning model }\end{array}$ & $\begin{array}{c}\text { ANFIS, RF } \\
\text { and LGP }\end{array}$ & $\begin{array}{l}\text { False prompts } \\
\text { and } \\
\text { unsuccessful } \\
\text { for results to } \\
\text { address }\end{array}$ & $\begin{array}{l}\text { Increasing in } \\
\text { detection for } \\
\text { accuracy }\end{array}$ & $\begin{array}{l}\text { Zainal et } \\
\text { al. }\end{array}$ \\
\hline 6 & $\begin{array}{l}\text { Integrating and } \\
\text { framework of } \\
\text { organisation }\end{array}$ & $\begin{array}{c}\text { Random } \\
\text { forest }\end{array}$ & $\begin{array}{l}\text { Cannot } \\
\text { detect } \\
\text { unknown } \\
\text { attacks }\end{array}$ & $\begin{array}{l}\text { Maximising } \\
\text { detection on } \\
\text { NIDS }\end{array}$ & $\begin{array}{l}\text { Zhang et } \\
\text { al. }\end{array}$ \\
\hline
\end{tabular}




\begin{tabular}{|c|c|c|c|c|c|}
\hline 7 & $\begin{array}{c}\text { The } \\
\text { complementary as } \\
\text { well as orthogonal } \\
\text { approach }\end{array}$ & $\begin{array}{l}\text { ID in Data } \\
\text { mining and } \\
\text { machine } \\
\text { learning. }\end{array}$ & $\begin{array}{c}\text { Beneficial } \\
\text { reduction in } \\
\text { simulated and } \\
\text { real } \\
\text { environment }\end{array}$ & $\begin{array}{l}\text { false positives } \\
\text { have been } \\
\text { reduced }\end{array}$ & $\begin{array}{l}\text { Pietraszek } \\
\text { et al. }\end{array}$ \\
\hline 8 & $\begin{array}{c}\text { Statistically ID } \\
\text { systematized }\end{array}$ & $\begin{array}{l}\text { attribute } \\
\text { Reduction } \\
\text { and Naïve } \\
\text { Bayes }\end{array}$ & $\begin{array}{l}\text { well-planned } \\
\text { reduction }\end{array}$ & $\begin{array}{l}\text { Exactness } \\
\text { optimal }\end{array}$ & $\begin{array}{c}\text { Mukherjee } \\
\text { et al }\end{array}$ \\
\hline 9 & $\begin{array}{c}\text { Neural network } \\
\text { comparison }\end{array}$ & $\begin{array}{c}\text { Data mining } \\
\text { algorithms }\end{array}$ & $\begin{array}{l}\text { Several } \\
\text { attacks } \\
\text { discussed }\end{array}$ & $\begin{array}{l}\text { Better detection and } \\
\text { will take time less }\end{array}$ & $\begin{array}{l}\text { Panda et } \\
\text { al. }\end{array}$ \\
\hline 10 & $\begin{array}{c}\text { Performances of } \\
\text { the neural networks } \\
\text { developed }\end{array}$ & $\begin{array}{l}\text { accuracy } \\
\text { shown in } \\
\text { Intrusion } \\
\text { detection }\end{array}$ & $\begin{array}{l}\text { Minimization of } \\
\text { the errors }\end{array}$ & $\begin{array}{c}\text { Structure } \\
\text { establish to } \\
\text { achieve great } \\
\text { accuracy }\end{array}$ & $\begin{array}{c}\text { Daejoon et } \\
\text { al }\end{array}$ \\
\hline
\end{tabular}

\section{Research Methodology}

4.1 Dataset assemblage: The data set is very large and we have taken only $10 \%$ of the data because otherwise it will become complicated. The data which we have taken is a very famous dataset in which there are both attack as well as the simple normal traffic. The dataset 4900000 in the KDD- CUP99 as vector connection. In the data mining we have available KDD data set and make traffic analysis on basis of traffic is it normal or abnormal. On line there are more available datasets and some does not filter because they are error free.

4.2 For Preprocessing: This is the process of filtering and Preprocessing in this either missing values have been removed in a good way. If there is bulky data have attacks like denial of service then it needs to first normalise the data also randomize the data. Lastly, there will be removal of noise in the preprocessing phase.

Conversion: There will transformation of data because data should be changed into numerical value from the categorial value.

Normalisation: It acts like a scale and also used for removing of errors.
Attribute predilection: For accuracy of all the attributes are basically not relevant to each other for this model. In this all the irrelevant and the redundant dataset are removed. For all the relevant attributes

filter have been used for to identify features.

4.3 (MI) Mutual Information attribute Selection: The random variable of mutual dependence or relation with one another have been determined by this technique of mutual information. The feature entropy has the very well relationship with the mutual information. The uncertainty of random variable is measured by the entropy.

4.4 ELM Classification: The data goes in layers for the series of neural network of a feedforward network.

Single/multiple of layers are setup of the machine learning algorithm and also, they are specific. The ELM

is also secondary name for these layers. There are several clustering classification and attribute engineering problems have been solved by this. The Input as well as output layer and have single or more hidden layers and it is a very well training, seeking and learning algorithm. The ELM has great advantage it can deal with complicated datasets very efficiently. Fig.2 Proposed model IDS is shown below. 


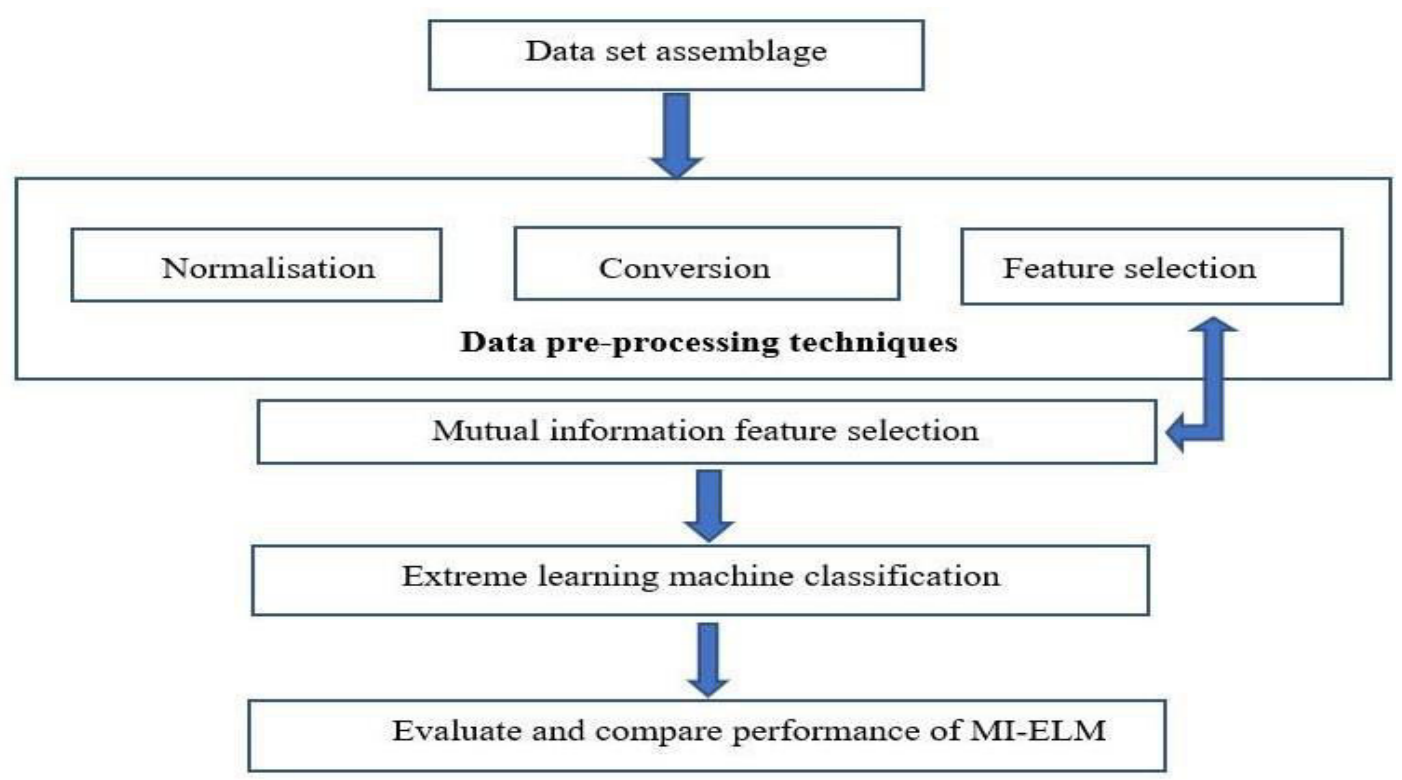

Fig1: Proposed IDS

4.5. Proposed Model: The suggested model has combined the Intrusion detection system with Mutual information as the attribute selection (feature) technique. The dataset has been collected from the online sources it was huge amount of data in dataset only $10 \%$ data has been taken into consideration with this providing better results. The preprocessing technique used for the removing noise and filter the data also can remove missing values. If the dataset will be clear don't have errors then then we don't need filtering. The data set contained 42 attributes it is very much data. The technique MI will make ranking of the attributes and we are choosing top 15 attributes. Class is known for the training set in data mining future can predict only the basis of previous data (original data). Extreme learning machine algorithm can classify the original dataset on traffic related normal or abnormal and training time algorithm can predict ELM actual value and predict value. The comparison taking place on matching between the two through accuracy. In our proposed model we have used the technique MI-ELM with the many classifiers like SVM, modified naïve Bayes, LP Boosting and Hybrid existing technique. The proposed technique shows increased accuracy with the existing classifiers.

5.1 Experimental Result: There are different types of parameters as taken under observation are as accuracy, correctly (C.I) classified instances, incorrectly (C.I) classified instances, the kappa integer statistic, precision, recall, F-measure, root mean square error and relative root error with classifiers of Support vector machine, Modified Naïve Bayes, Boosting, Hybrid and proposed MI-ELM.
5.2 Illustration Evaluation: There are several parameters used for description estimation. Confusion matrices in which values are predict through an algorithm and other one is actual values. The results are analyzed and there are total 1260 instances in this dataset.

\subsection{Implementation MI-ELM:}

In this to implement the several classification algorithms SVM, MNB, Boosting, Hybrid and mutual informationExtreme learning machine classification. The mutual information technique is used and makes priority of the attributes with this dimensionality reduces as well as less time. There has been shown different screen shots of the figures in below. 


\section{Fig 4.1 Snapshot of Selecting the dataset}

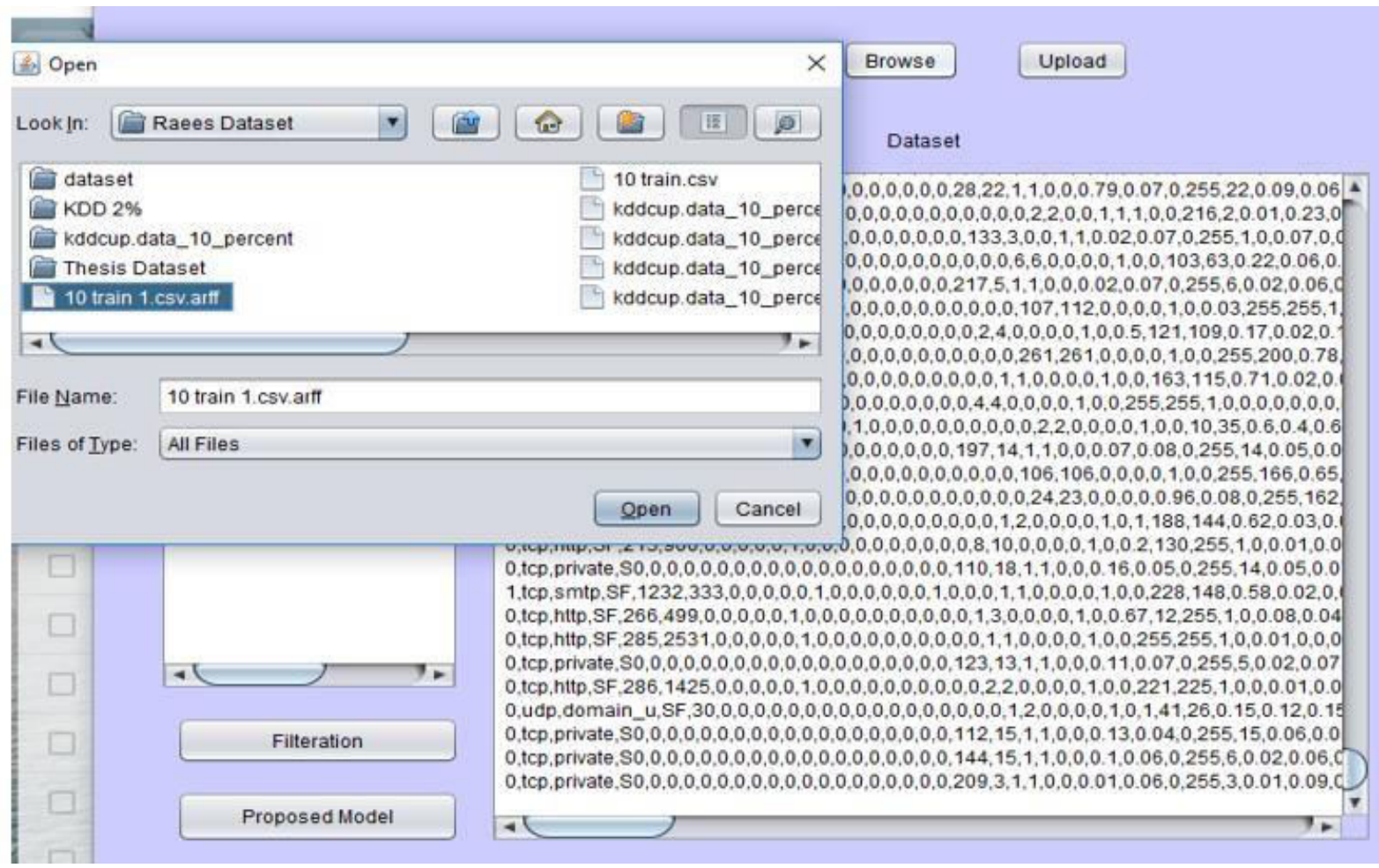

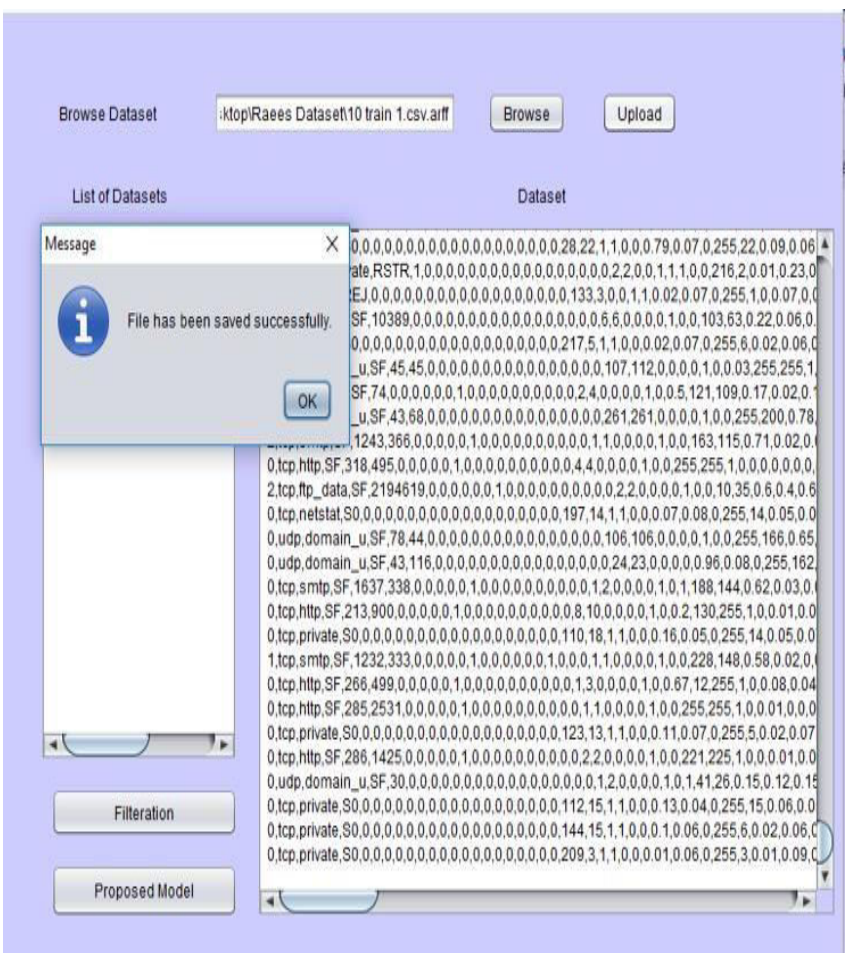

Fig 4.2 Snapshot Data is uploaded and the file has been saved successfully

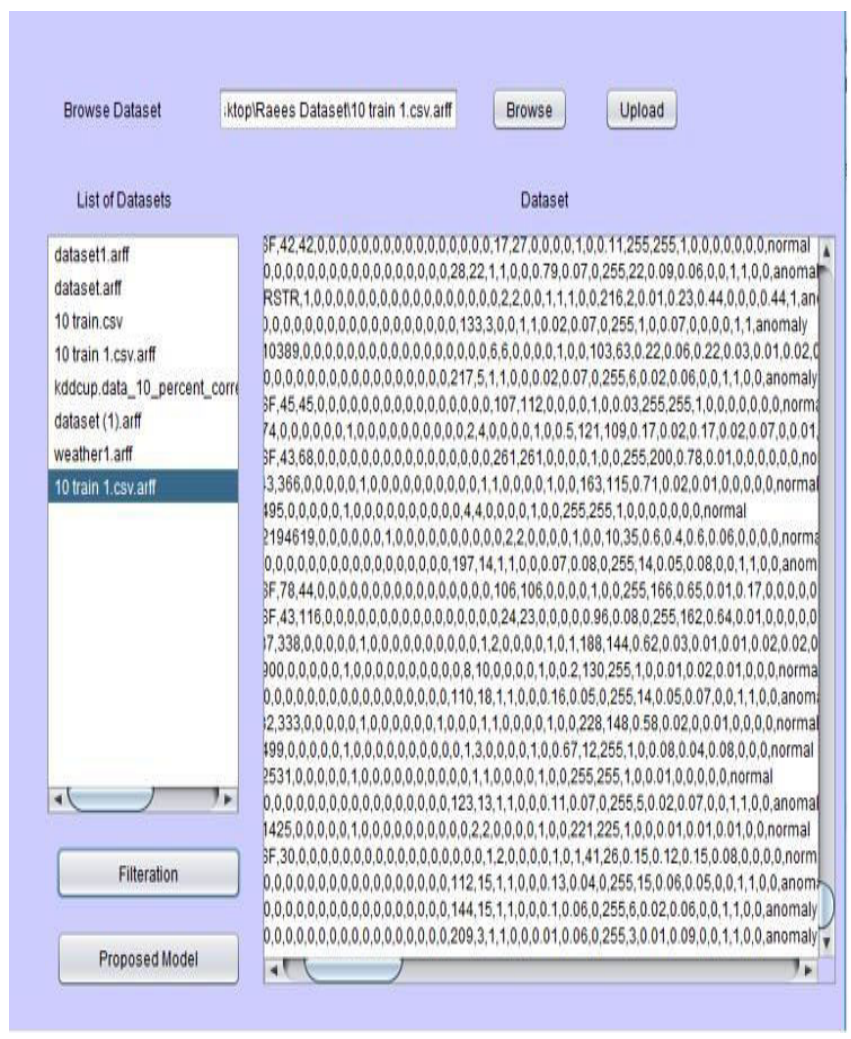

Fig 4.3 Snapshot of showing the dataset content and filtration 


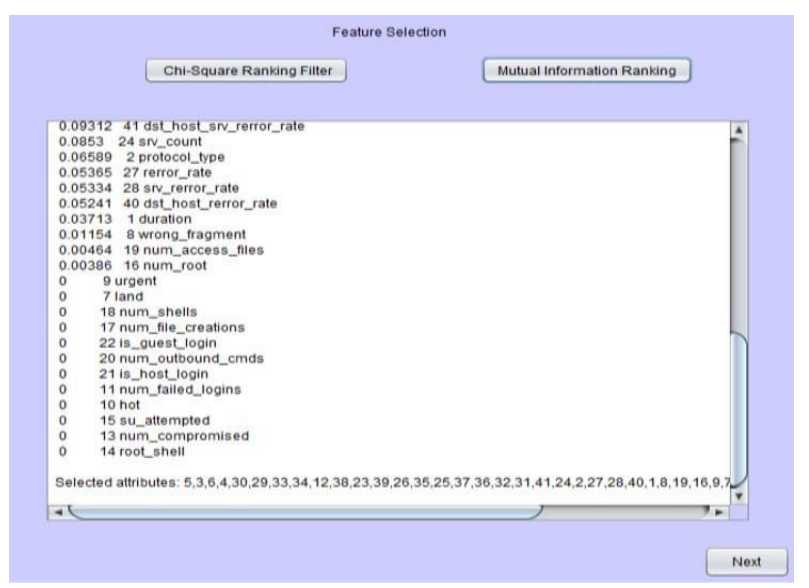

Fig 4.4 Snapshot of the Feature ranking using proposed Mutual information feature selection technique

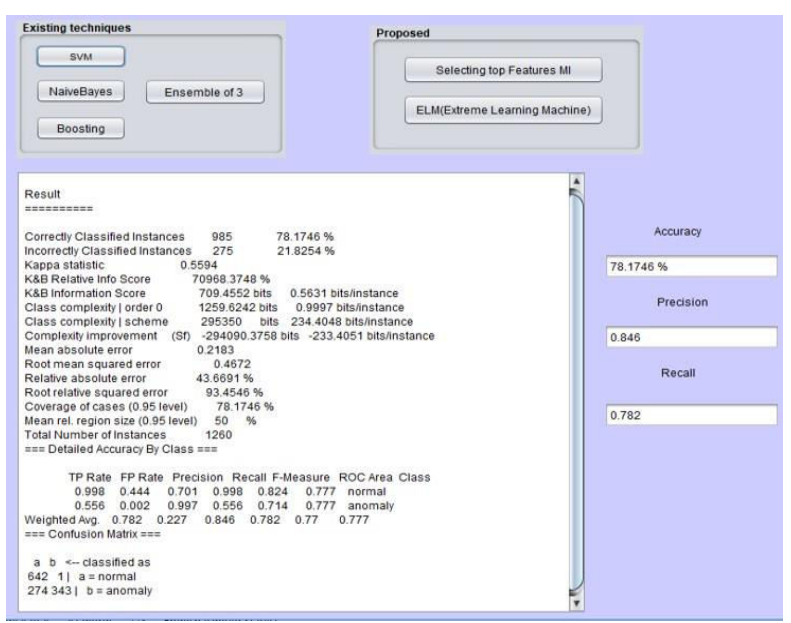

Fig 4.5 Results of SVM base technique

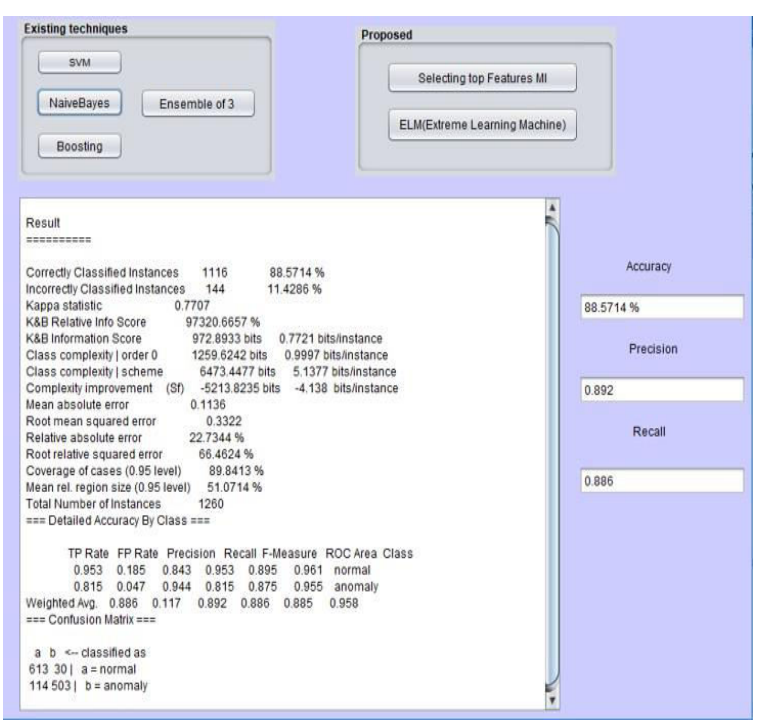

Fig 4.6 Results of naïve Bayes base technique

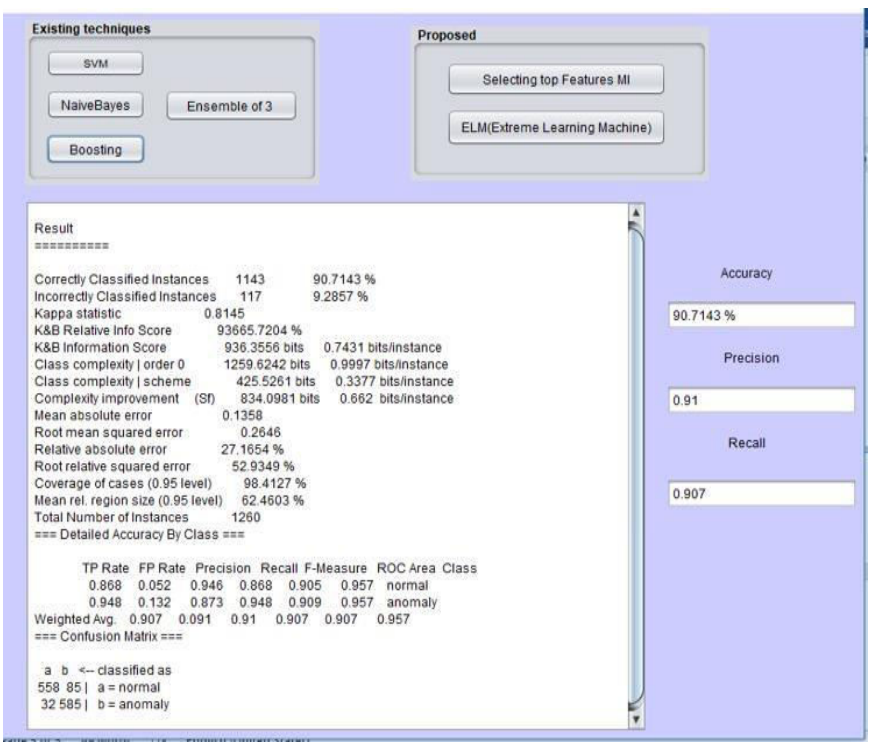

\section{$\begin{array}{lllll}\text { Fig } & 4.7 & \text { Results of } & \text { Boosting base technique }\end{array}$}

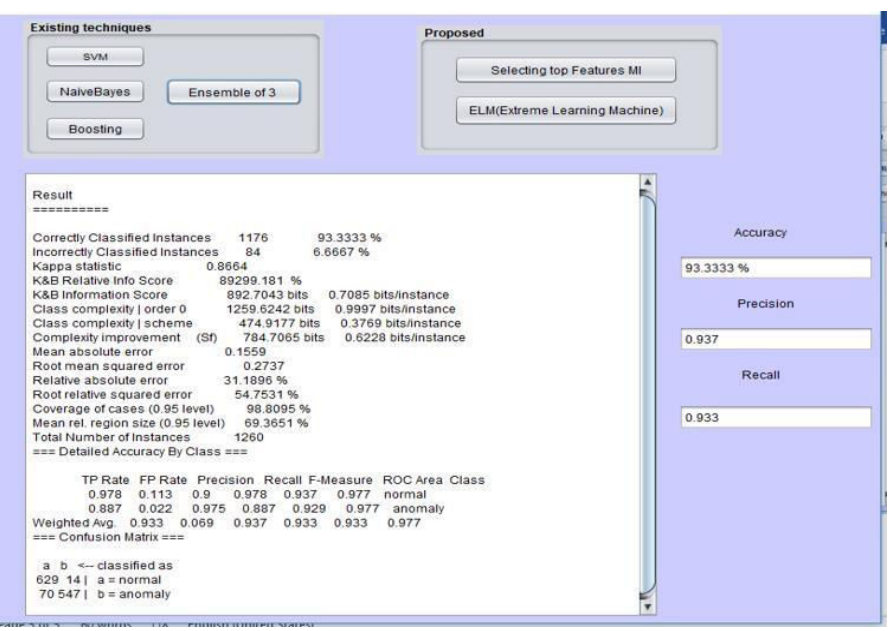

Fig 4.8 Hybrid technique results

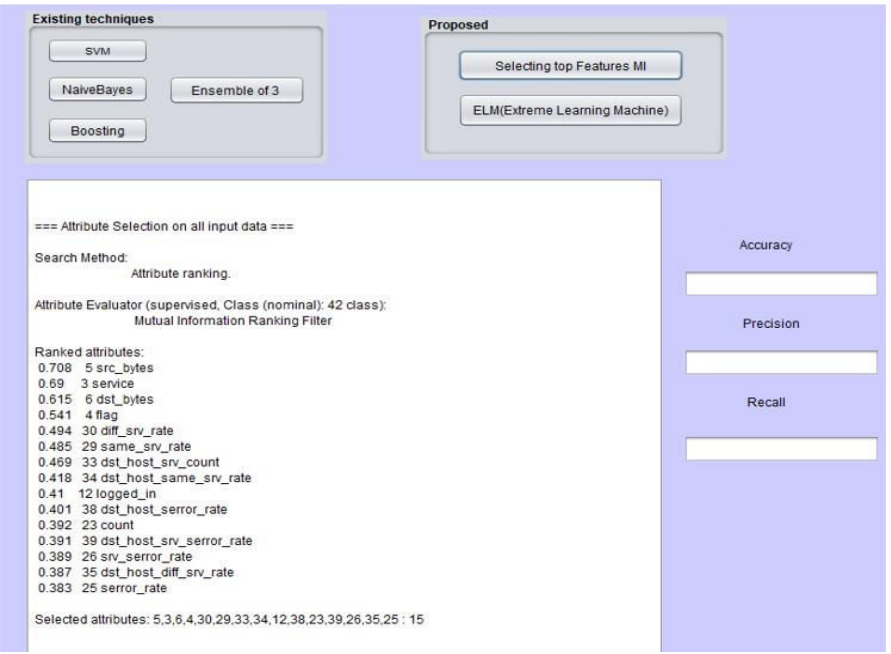

Fig 4.9 The top fifteen (15) features selection using MI 


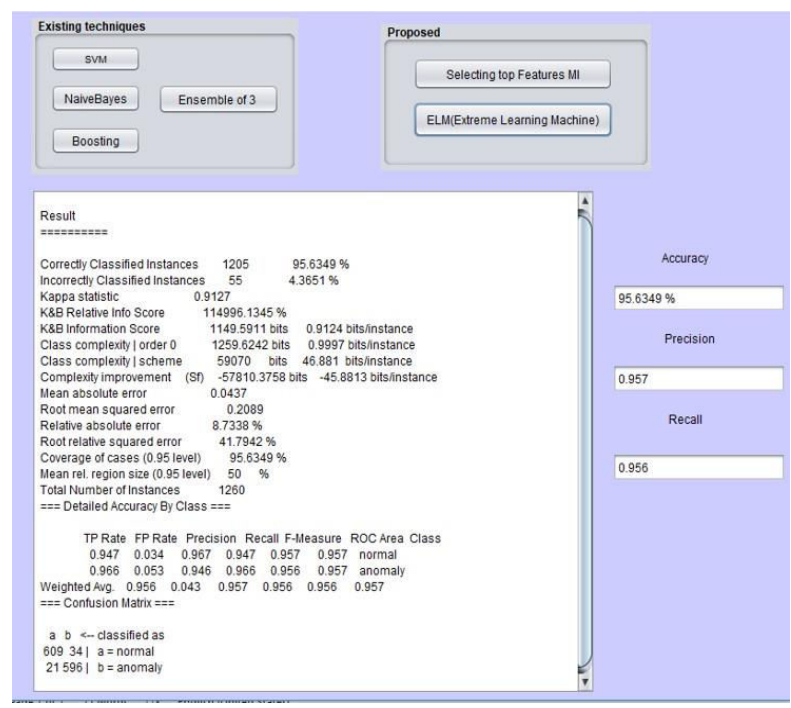

Fig 4.10 The Proposed ELM technique results

5.4 Results: The analysis will be making of attributes with ranking of the feature optimisation or direct classification. There are different parameters like Precision, Recall. F-measure, accuracy, the Kappa integer statistic, Incorrectly and Correctly (CI) classified instances, RMSE (Root of Mean square erratum or error) and RRE (Root relative of error). The Mutual information attribute selection is applying with ELM classification and parameters are briefly described below.

a) Accuracy: It is the total perfection of the standard value and is the result of specification.

$$
\mathbf{A}=\frac{T p+T n}{T p+F p+T n+F n}
$$

b) Precision: It is the calculation and a measurement also show the clearness. The predict as well as actual values are positive.

$$
\mathbf{P}=\frac{T p}{T p+F p}
$$

c) Recall: It was recollection of the intelligent systems and produce optimal solutions.

$$
\mathbf{R}=\frac{T p}{T p+F n}
$$

d) F-Measure: Both recall and precision consider the best test to calculate.

$$
\text { F-Measure }=2 /(1 / P+1 / R)
$$

\section{e) Detection Rate:}

$$
\mathbf{D . R}=\frac{T p}{T p+F n}
$$

\section{f) False Positive Rate:}

$$
\mathbf{F P R}=\frac{F p}{T p+F n}
$$

g) Kappa statistic: It shows the which are near to unity have more accuracy.

h) Correctly classified Instances: The sum of the diagonal values has been classified into rightly classified instances. It has from directly from confusion matrices. The values for correctly classified should always greater from incorrect classified instances.

i) Incorrectly classified instances: Similarly, they have classified through the sum of diagonal elements from confusion matrices.

j) Root mean square error: It is actually the standard deviation of a prediction and of errors. The frequently used between in difference estimated and the predicted values.

k) Root relative error: It will normalise the total square error and divided so get normalise by square root of prediction.

\subsection{Results of algorithms:}

5.5.1 Accuracy: And for the accuracy Table 5.1 shows accuracy of SVM

(78.17\%), MNB (88.75\%), Boosting (90.71\%), Hybrid existing (93.33\%) and Proposed MI-ELM (95.63\%/). Among all these classifiers the proposed technique shows more accuracy $95.63 \%$ as shown in table 5.1

Table 5.1 shows group of classifiers with accuracy

\begin{tabular}{|l|l|l|l|l|l|}
\hline $\begin{array}{l}\text { Para } \\
\text { meter s }\end{array}$ & $\begin{array}{l}\text { SV } \\
\text { M }\end{array}$ & $\begin{array}{l}\text { Naï ve } \\
\text { Bay es }\end{array}$ & $\begin{array}{l}\text { Boo } \\
\text { sting }\end{array}$ & $\begin{array}{l}\text { Hybr } \\
\text { id Tech } \\
\text { nique }\end{array}$ & $\begin{array}{l}\text { Prop } \\
\text { osed } \\
\text { MI- EL } \\
\text { M }\end{array}$ \\
\hline $\begin{array}{l}\text { Accu } \\
\text { racy }\end{array}$ & $\begin{array}{l}78 . \\
17\end{array}$ & $\begin{array}{l}88 . \\
\%\end{array}$ & $\begin{array}{l}90.7 \\
1 \%\end{array}$ & $\begin{array}{l}93.33 \\
\%\end{array}$ & $\begin{array}{l}95.6 \\
3 \%\end{array}$ \\
& & & & & \\
\end{tabular}




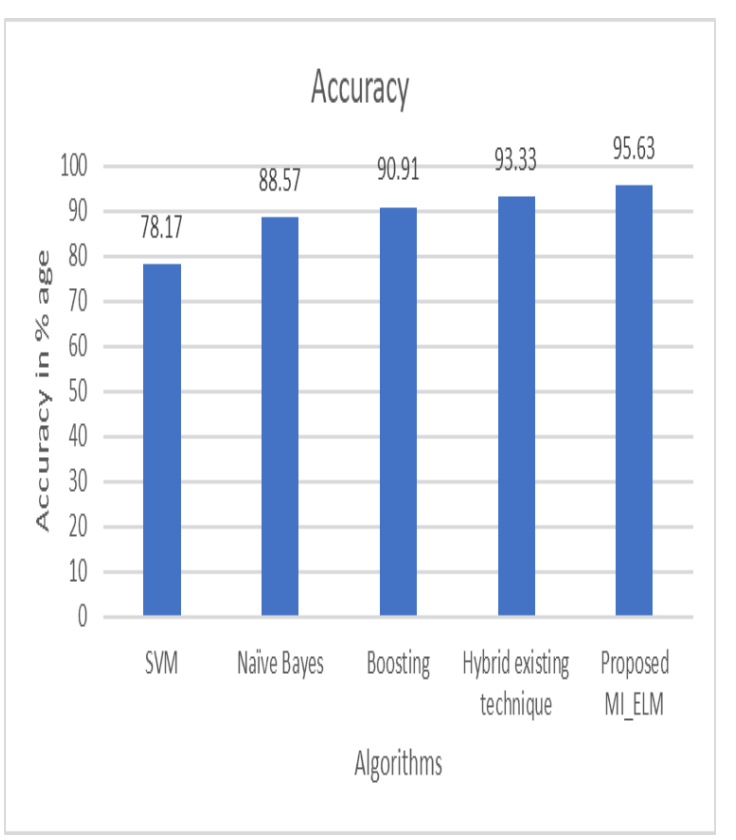

Fig 5.1 Graphical representation of accuracy

5.5.2 The Correctly and the Incorrectly classified instances: In table 5.2 both have been categorised into two rows and classifiers are in different columns. The values of correctly should always be greater than incorrectly so that it provides

better results.

Table 5.2 Comparison both correctly and incorrectly classified instances

\begin{tabular}{|l|l|l|l|l|l|}
\hline $\begin{array}{l}\text { Param } \\
\text { eters }\end{array}$ & $\begin{array}{l}\text { SV } \\
\text { M }\end{array}$ & $\begin{array}{l}\text { Naï } \\
\text { ve } \\
\text { Ba } \\
\text { yes }\end{array}$ & $\begin{array}{l}\text { Boos } \\
\text { ting }\end{array}$ & $\begin{array}{l}\text { Hyb } \\
\text { rid }\end{array}$ & $\begin{array}{l}\text { Prop } \\
\text { osed } \\
\text { MI- } \\
\text { ELM }\end{array}$ \\
\hline $\begin{array}{l}\text { Correc } \\
\text { tly } \\
\text { classif } \\
\text { ied } \\
\text { instan } \\
\text { ces }\end{array}$ & $\begin{array}{l}98 \\
5\end{array}$ & $\begin{array}{l}111 \\
6\end{array}$ & 1143 & $\begin{array}{l}117 \\
6\end{array}$ & 1205 \\
\hline $\begin{array}{l}\text { Incorr } \\
\text { ectly } \\
\text { classif } \\
\text { ied } \\
\text { instan } \\
\text { ces }\end{array}$ & $\begin{array}{l}27 \\
5\end{array}$ & 114 & 117 & 84 & 55 \\
\hline
\end{tabular}

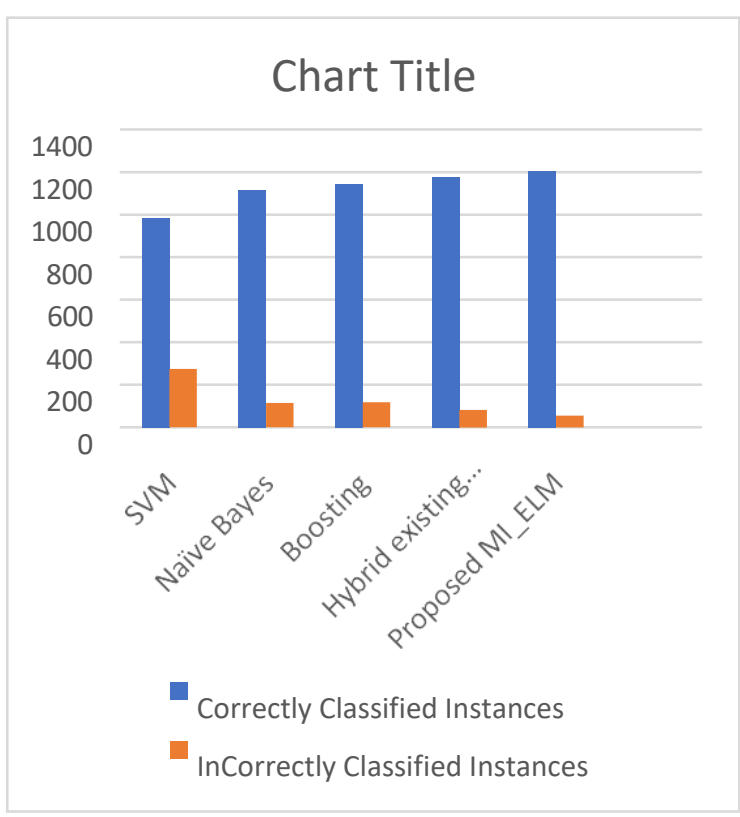

\section{Fig 5.2 Correctly and incorrectly} classified instances

5.3.3 The Kappa Statistic Values (KSV): The value .91 is has more accuracy among the classifiers. Also, the values which are near to shows always much and greater accuracy. In table 5.3 below has shown.

Table 5.3 shows accuracy is maximum by proposed model in table as well as graph

\begin{tabular}{|l|l|l|l|l|l|}
\hline $\begin{array}{l}\text { Param } \\
\text { eters }\end{array}$ & $\begin{array}{l}\text { SV } \\
\text { M }\end{array}$ & $\begin{array}{l}\text { Naï } \\
\text { ve } \\
\text { Ba } \\
\text { yes }\end{array}$ & $\begin{array}{l}\text { Boos } \\
\text { ting }\end{array}$ & $\begin{array}{l}\text { Hyb } \\
\text { rid }\end{array}$ & $\begin{array}{l}\text { Prop } \\
\text { osed } \\
\text { MI- } \\
\text { ELM }\end{array}$ \\
\hline $\begin{array}{l}\text { Kappa } \\
\text { statisti c }\end{array}$ & $\begin{array}{l}.55 \\
94\end{array}$ & .77 & .81 & .86 & .9127 \\
\hline
\end{tabular}

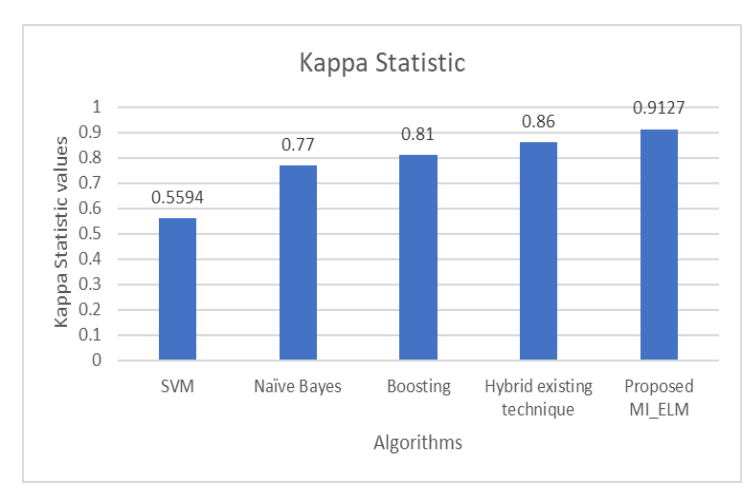

Fig 5.3 Kappa statistic values 
5.3.3 Precision, Recall, F-Measure: In all these three parameters proposed MI-ELM shows more values in every parameter.

Table 5.3 Precision, Recall and FMeasure

\begin{tabular}{|l|l|l|l|l|l|}
\hline $\begin{array}{l}\text { Param } \\
\text { eters }\end{array}$ & $\begin{array}{l}\text { SV } \\
\text { M }\end{array}$ & $\begin{array}{l}\text { Naï } \\
\text { ve } \\
\text { Ba } \\
\text { yes }\end{array}$ & $\begin{array}{l}\text { Boos } \\
\text { ting }\end{array}$ & $\begin{array}{l}\text { Hyb } \\
\text { rid }\end{array}$ & $\begin{array}{l}\text { Prop } \\
\text { osed } \\
\text { MI- } \\
\text { ELM }\end{array}$ \\
\hline $\begin{array}{l}\text { Precisi } \\
\text { on }\end{array}$ & $\begin{array}{l}.84 \\
6\end{array}$ & $\begin{array}{l}.89 \\
2\end{array}$ & .91 & .937 & .957 \\
\hline Recall & $\begin{array}{l}.78 \\
2\end{array}$ & $\begin{array}{l}.88 \\
6\end{array}$ & .907 & .933 & .956 \\
\hline $\begin{array}{l}\text { F- } \\
\text { Measu } \\
\text { re }\end{array}$ & 3 & $\begin{array}{l}.88 \\
.88\end{array}$ & .648 & .938 & .956 \\
\hline
\end{tabular}

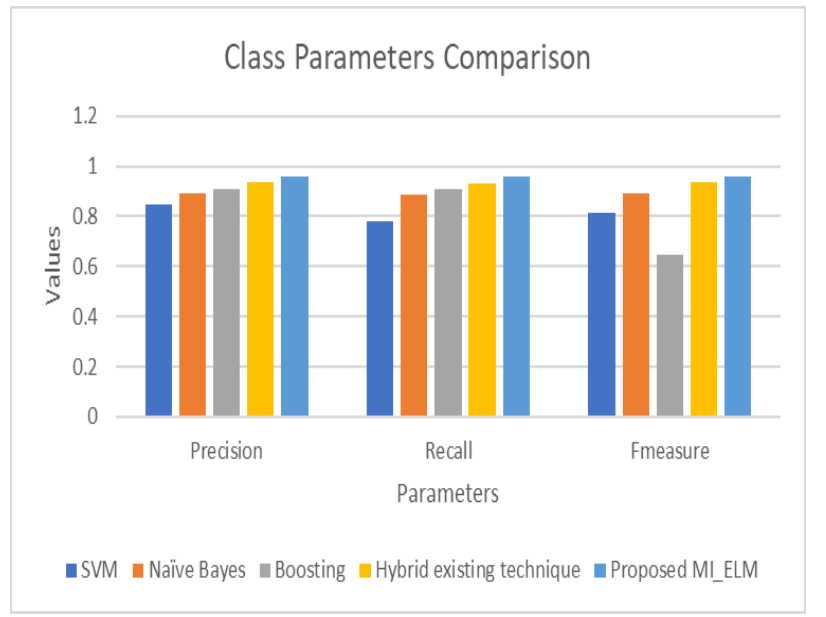

Fig 5.4 Graphical representation of Precision, Recall, F-measure

5.4.4 RMSE (Root of Mean square erratum or error) and RRE (Root relative of error): In graph and table 5.1 the proposed technique shows less error rates in comparison to others like SVM, MNB, Boosting and Hybrid technique.

\begin{tabular}{|l|l|l|l|l|l|}
\hline $\begin{array}{l}\text { Param } \\
\text { eters }\end{array}$ & $\begin{array}{l}\text { SV } \\
\text { M }\end{array}$ & $\begin{array}{l}\text { Naï } \\
\text { ve } \\
\text { Ba } \\
\text { yes }\end{array}$ & $\begin{array}{l}\text { Boos } \\
\text { ting }\end{array}$ & $\begin{array}{l}\text { Hyb } \\
\text { rid }\end{array}$ & $\begin{array}{l}\text { Prop } \\
\text { osed } \\
\text { MI- } \\
\text { ELM }\end{array}$ \\
\hline $\begin{array}{l}\text { Root } \\
\text { mean } \\
\text { square } \\
\text { error }\end{array}$ & .46 & .33 & .26 & .27 & .2089 \\
\hline $\begin{array}{l}\text { Root } \\
\text { relativ } \\
\text { e error }\end{array}$ & $\begin{array}{l}93 . \\
45\end{array}$ & $\begin{array}{l}66 . \\
46\end{array}$ & $\begin{array}{l}52.9 \\
3\end{array}$ & $\begin{array}{l}54 . \\
75\end{array}$ & 41.79 \\
\hline
\end{tabular}

Table 5.4 RMSE and RRE

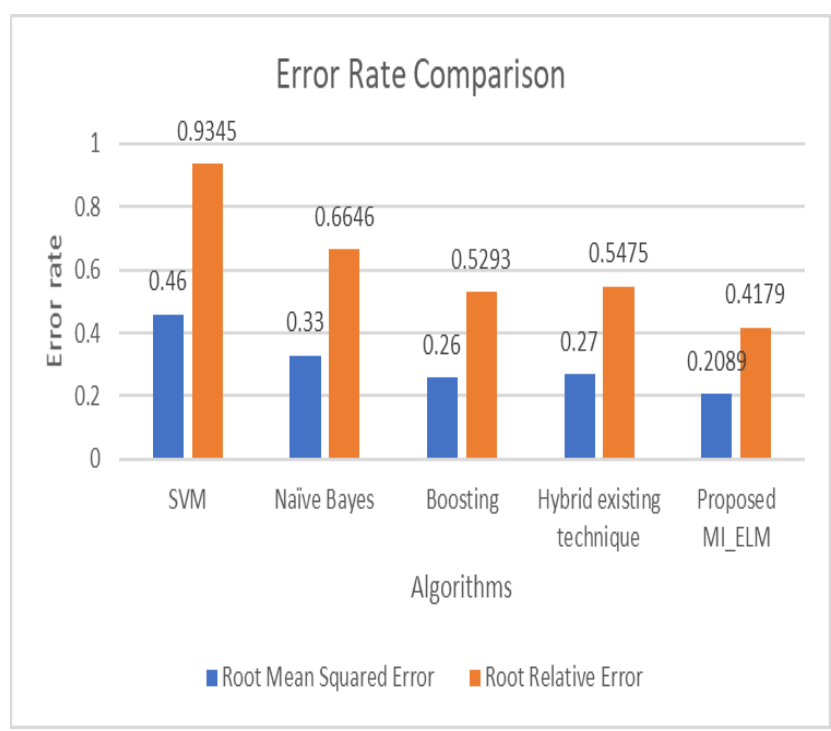




\section{REFERENCES:}

[1] Thaseen $\mathrm{S}$ et al. Integrated Intrusion Detection Model Using Chi-Square Feature Selection and Ensemble of Classifiers. Arabian Journal for Science and Engineering 2018, 44(4); 3357-3368.

[2] Kausar N et al. An Approach towards Intrusion Detection using PCA Feature Subsets and SVM. International Conference on Computer \& Information Science (ICCIS) lEEE 2012; 978-1-4673- 1938-6/12.

[3] Dhanabal L et al. A Study on NSL-KDD Dataset for Intrusion Detection System Based on Classification Algorithms" International Journal of Advanced Research in Computer and Communication Engineering (June 2015) Vol. 4, Issue 6,

[4] Akashdeep et al. A feature reduced intrusion detection system using ANN classifier Expert Systems with Applications (2017); 88: S249-257

[5] Zainal A et al. Ensemble of One-class Classifiers for Network Intrusion Detection System. IEEE (2008); 9780-7695-3324-7/08.

[6] Zhang J et al. A Hybrid Network Intrusion Detection Technique Using Random Forests. Proceedings of the First International Conference on Availability, Reliability and Security (ARES'06) IEEE 2006; 0-7695-2567-9/06.

[7] Pietraszek T, Tanner A. Data mining and machine learning Towards reducing false positives in intrusion detection. Information Security Technical Report (2005) 10, 169-183.

[8] Mukherjee S, Sharma N. Intrusion Detection using Naive Bayes Classifier with Feature Reduction. Procedia Technology (2012); 4:119 - 128.

[9] Mrutyunjaya Panda and Manas Ranjan NETWORK INTRUSION DETECTION USING NAÏVE BAYES IJCSNS International Journal of Computer Science and Network Security (December 2007), VOL.7 No.12.

[10] Daejoon Joo et al The neural network models for IDS based on the asymmetric costs of false negative errors and false positive errors Expert Systems with Applications 25 (2003) 69-75. 